\title{
Ethiek in en van kwalitatief onderzoek
}

\author{
Stefan Verweij ${ }^{*}$
}

T. Miller, M. Birch, M. Mauthner \& J. Jessop (Eds.), Ethics in qualitative research. London: Sage, 2012 (2nd ed.), 208 pagina's, ISBN 978-1-44621-089-5, \$ 47,00 (pbk); ISBN 978-1-44621-088-8, \$120,00 (hbk).

In november 2012 publiceerde de Commissie Levelt haar eindrapport van het onderzoek naar de frauduleuze onderzoekspraktijken van sociaalpsycholoog Diederik Stapel. Integriteit en ethiek in sociaalwetenschappelijk onderzoek kregen naar aanleiding van deze kwestie in de media en de wetenschap volop aandacht. Een van de aanbevelingen in het rapport is dat stafleden en promovendi bij hun aanstelling worden geïnformeerd over de ethische normen binnen hun instelling en dat promovendi worden onderwezen in de ethiek (p. 57). Een andere aanbeveling is dat onderzoeksdata - zowel ruwe data als datasets - worden gearchiveerd en op aanvraag ter beschikking worden gesteld aan andere wetenschapsbeoefenaren (p. 58).

Deze aanbevelingen zijn illustratief voor de nieuwe ontwikkelingen waarmee kwalitatieve onderzoekers te maken hebben. Een van de belangrijkste doelen van de tweede editie van het boek Ethics in qualitative research - onder redactie van Tina Miller, Maxine Birch, Melanie Mauthner en Julie Jessop - is om de ethische dilemma's die kleven aan deze ontwikkelingen, te schetsen. Dit is wat deze tweede editie onderscheidt van de eerste, die dateert uit 2002. Daarnaast gaat het boek in op een reeks andere ethische vraagstukken, die ook in de vorige editie aan de orde kwamen; deze zijn niet minder actueel, maar hangen minder samen met de recente ontwikkelingen. De schrijvers willen dit vooral doen door het presenteren van hun persoonlijke ervaringen. Het boek wil interessant zijn voor een breed lezerspubliek van onderzoekers die kwalitatief onderzoek willen begrijpen en uitvoeren op een manier die ethisch, theoretisch en praktisch geïnformeerd is (p. 9). De drie nieuwe hoofdstukken in het boek (2, 10 en 11) gaan specifiek in op de ethische dilemma's die ontstaan als gevolg van de recente ontwikkelingen. Deze ontwikkelingen, die door Miller worden geschetst in het tweede hoofdstuk, betreffen vooral een toename van ethische review en regulatie en ontwikkelingen in informatietechnologie en software (p. 31). Echter, Miller geeft in hetzelfde hoofdstuk over 'reconfiguring research relationships' aan dat ethische commissies met hun 'pre-study reviews' (p. 30) beperkingen opleggen aan kwalitatief onderzoek dat van nature juist een flexibel en daarom soms onvoorspelbaar karakter heeft. Dit roept volgens Miller belangrijke ethische vragen op, onder andere met betrekking tot de relatie tussen onderzoeker en respondent: in hoeverre kun je als onderzoeker je respondenten nog vertrouwelijkheid van de data garanderen? En

* Stefan Verweij, MSc is als promovendus verbonden aan de onderzoeksgroep Governance of Complex Systems van de afdeling Bestuurskunde van de Erasmus Universiteit Rotterdam. E-mail: verweij@fsw.eur.nl. 
wat betekent het voor de mate waarin respondenten zich openstellen in interviews als ethische commissies eisen dat data publiekelijk beschikbaar worden gesteld? Miller geeft hiermee inzicht in de ethische dilemma's die kleven aan aanbevelingen zoals die van de Commissie Levelt. Ook de toegenomen digitalisering heeft haar invloed op de relatie tussen onderzoeker en onderzochte. Aan de pluszijde kan het de emancipatie van gemarginaliseerde groepen helpen. De keerzijde is dat bijvoorbeeld het beschermen van zowel de respondent als de onderzoeker, in termen van onder andere anonimiteit en vertrouwelijkheid, bemoeilijkt wordt. Miller sluit haar hoofdstuk af met enkele praktische tips over hoe kwalitatieve onderzoekers hiermee kunnen omgaan.

In hoofdstuk 10 gaat Mauthner verder in op de ethische en morele gevolgen van de toegenomen digitalisering, specifiek wat betreft 'digital data sharing' (p. 157). Tegen de achtergrond van wetenschappelijke (denk aan de aanbeveling van de Commissie Levelt naar aanleiding van de casus Stapel), morele en economische argumenten om data publiekelijk beschikbaar te stellen, bespreekt zij de ethische dilemma's die eraan kleven. Wat betekent het bijvoorbeeld voor 'seeking informed consent' (p. 162) en het bewaken van anonimiteit? Van kwalitatieve onderzoekers vraagt dit om bepaalde methodologische keuzes te maken (bijvoorbeeld in de interviewmethoden en -technieken en de transcriptie en analyse van interviews) om bijvoorbeeld anonimiteit te garanderen. Dit kan kwalitatieve onderzoekers dwingen zich te conformeren aan wetenschappelijke, morele en economische waarden in de uitvoering van hun onderzoek die zij mogelijk zelf niet aanhangen. Dit is op zichzelf een belangrijk ethisch vraagstuk. In het slothoofdstuk (hoofdstuk 11) geven de editors van het boek dan ook aan dat de toegenomen ethische standaardisering en digitalisering in scherp contrast staat met de overtuiging van de hoofdstukauteurs dat kwalitatief onderzoek nu juist geen 'one size fits all'-productie is (p. 177). Het hoofdstuk eindigt met een reeks reflexieve behulpzame vragen die onderzoekers kunnen helpen om hun ethische praktijk binnen de eigen onderzoeksbenadering te evalueren en te ontwikkelen.

De overige hoofdstukken behandelen thema's die ook waren opgenomen in de eerste editie van het boekwerk. Deze hoofdstukken zijn geschreven vanuit een meer feministisch perspectief, zoals de auteurs vaak ook expliciet vermelden. In het eerste hoofdstuk verbinden Edwards en Mauthner theoretische ethische modellen aan de praktijk van feministisch onderzoek. In het derde hoofdstuk gaan Gillies en Alldred in op epistemologische debatten binnen het feminisme. Zij beargumenteren dat deze debatten belangrijke implicaties hebben voor de invulling van de feministische agenda, waarbij zij drie onderwerpen onderscheiden: 'representing women' (p. 49), 'initiating personal change through action research' (p. 51) en 'deconstructing and undermining "knowledge” structures' (p. 55). Deze twee hoofdstukken voorzien daarmee in de context voor de andere hoofdstukken, waar meer concreet op die ethische praktijk van kwalitatief onderzoek wordt ingegaan. Miller en Bell behandelen vervolgens in hoofdstuk 4 de 'informed consent' en beargumenteren onder andere dat dit een continu proces is en niet iets wat alleen aan het begin van een interview wordt geregeld. Vervolgens behandelen Bell en Nutt ethische dillema's die kunnen ontstaan in de relatie tussen onderzoek en praktijk, bijvoorbeeld het dilemma van vertrouwelijkheid versus 
bescherming van een respondent tegen zichzelf. In hoofdstuk 6 behandelen Birch en Miller ethische dilemma's rondom respondentparticipatie in onderzoek. Duncombe en Jessop behandelen in hoofdstuk 7 'doing rapport and the ethics of faking friendship' (p. 108). De hoofdstukken 8 en 9 verkennen de wijdere ethische implicaties van kwalitatief onderzoek. Achtereenvolgens wordt het belang benadrukt van het verschil tussen 'knowing well' en 'knowing responsibly' (p. 123) en het besef dat onderzoekers grotendeels onoverkomelijk westerse, modernistische waarden (laten) reproduceren in kwalitatief onderzoek, onder andere in interviews.

De casus Stapel uit de inleiding maakte pijnlijk duidelijk wat de gevolgen zijn van de actuele 'publish or perish'-cultuur, die in de wetenschap steeds significanter wordt: onderzoekers worden instrumenteler in hun praktijken. Ethische vraagstukken zijn dan vaak buiten het blikveld of worden als lastig en tijdrovend beschouwd. Dit boek geeft inzicht in de ethische vraagstukken en houdt kwalitatieve onderzoekers een spiegel voor om te reflecteren op hun eigen praktijken. Het levert daarmee een relevante bijdrage aan de discussie over ethiek in kwalitatief onderzoek en voorziet daarbij in een aantal relevante, kritische reflecties op de tendensen van digitalisering en standaardisatie en op de formalisatie van ethische normen.

Het feit dat veel van deze hoofdstukken expliciet vertrekken vanuit een feministische agenda doet weinig af aan de relevantie van de besproken thema's en onderwerpen voor niet-feministische kwalitatieve onderzoekers, zoals ikzelf. Veel uitgangspunten, zoals 'contextualized reasoning' en 'conducting research about personal lives, grounded in individual experiences' (p. 5-6), zijn ook meer in het algemeen herkenbaar voor interpretatieve onderzoekers. Maar het vraagt meer inspanning van de lezer om de wijdere implicaties te overzien. Houd er verder ook rekening mee dat kwalitatief onderzoek in dit boek vooral betekent 'interviewen', met hoofdstuk 8 als meest verfrissende uitzondering, waar ook wordt stilgestaan bij de ethische dilemma's in data-analyse (van interviews, dat wel) en rapportage.

In het boek wordt terloops een onderscheid gemaakt tussen ethiek in kwalitatief onderzoek en ethiek van kwalitatief onderzoek. Op die twee invalshoeken hinkt het boek ook een beetje. De tweede heeft nauwer verband met de feministische agenda en de eerste heeft meer te maken met de genoemde actuele ontwikkelingen. Wat mij betreft had dat ook in de titel naar voren mogen komen. Ik zou het boek dan ook vooral aanbevelen aan kwalitatieve onderzoekers (interviewers) die zich bewust willen worden van de ethische dilemma's als gevolg van onder andere de toenemende standaardisering en digitalisering van onderzoek.

\section{Literatuur}

Commissie Levelt (2012). Falende wetenschap: de frauduleuze onderzoekspraktijken van sociaal-psycholoog Diederik Stapel.

Mauthner, M., Birch, M., Jessop, J. \& Miller, T. (Eds.) (2002). Ethics in qualitative research. London: Sage. 